\title{
Ergonomia e complexidade: o trabalho do gestor na agricultura orgânica na região de Campinas - SP
}

\author{
Complexity and ergonomy: the manager work at the organic agriculture in Campinas - SP Brazil
}

\author{
Sandra Francisca Bezerra Gemma ${ }^{\mathrm{I}}$ Mauro José Andrade Tereso ${ }^{\mathrm{II}}$ Roberto Funes Abrahão ${ }^{\mathrm{III}}$
}

\section{RESUMO}

A lacuna de pesquisas sobre o trabalho humano na agricultura orgânica motivou este estudo, que teve por objetivos caracterizar e compreender o trabalho do gestor no manejo orgânico da produção agrícola. A pesquisa de campo, realizada em duas etapas, permitiu investigar o trabalho dos gestores em Unidades de Produção Agrícola Orgânica (UPAO) do interior de São Paulo, por meio da adaptação do método da Análise Ergonômica do Trabalho (AET) e de entrevistas estruturadas. Os dados de campo foram posteriormente interpretados à luz da Teoria da Complexidade (TC). Constatouse que o gestor da agricultura orgânica é responsável por um macrossistema (produção vegetal, produção animal, processamento e serviços), atuando concomitantemente como administrador e executor do trabalho. A grande variedade de produtos oferecidos pela agricultura orgânica gera a necessidade de expertise do gestor no trato com as diferentes espécies vegetais e na sua integração com os demais sistemas de produção. Concluiu-se que o trabalho executado pelos gestores é caracterizado pela diversidade de atividades que precisam ser realizadas e integradas dentro do macrossistema, em associação com os determinantes do processo de certificação num contexto de falta de tecnologia adequada e de cenários incertos e variados. Cabe ao gestor incorporar e transformar em práticas de trabalho os preceitos ecológicos, econômicos e sociais de sustentabilidade, que podem ser contraditórios entre si, integrar essas múltiplas dimensões, por meio do desenvolvimento e da conexão de variados saberes $e$ competências, e elaborar estratégias para superar as diversas dificuldades relacionadas com os aspectos tecnológicos, financeiros e humanos na agricultura orgânica.

Palavras-chave: agricultura orgânica, teoria da complexidade de Edgar Morin, ergonomia, condições de trabalho.

\begin{abstract}
The lack of research about the human work at the Organic agriculture stimulated this study, which purpose was to characterize and understand the manager's job in managing organic farming. The field research was carried out in two stages, and allowed to investigate managers' work at organic agricultural production units (UPAO) from the interior of Sao Paulo state, through an adaptation of the ergonomics' analysis method (AET) and structured interviews. The data collected were further interpreted in the light of the complexity theory (TC). It was possible to infer that the organic agricultural manager is accountable for a macro production system (vegetable, animal, processing and services), where the manager acts simultaneously as the administrator and also as the job performer. The wide products variety offered by the organic agriculture demands an expertise from the manager in order to deal with the different vegetable specimens and their integration with the remaining production systems. It was concluded that the work performed by the managers is characterized by the diversity of activities, that need to be prepared and integrated within a macro system, associated with the certification process determinants, in absence of suitable technology context and uncertain and multiple scenarios. It comes to the manager to incorporate and to transform into work practices the ecological, economical and social sustainability principles, which can be contradictory among each other. They can integrate these multiple dimensions through the development and connection of several competences and knowledge, as well as elaborate strategies to overcome multiple difficulties related to the organic agriculture's technological, financial and human aspects.
\end{abstract}

Key words: organic agriculture, Edgar Morin complexity theory, Ergonomics (environmental health), human engineering, working conditions.

'Faculdade de Ciências Aplicadas, Universidade Estadual de Campinas (UNICAMP), Rua Pedro Zaccaria, 1300, Jd. Sta.Luiza, 13484-350, Limeira, SP, Brasil. E-mail: sandra.gemma@fca.unicamp.br. Autor para correspondência.

IIPlanejamento e Desenvolvimento Rural Sustentável, Faculdade de Engenharia Agrícola, UNICAMP, Campinas, SP, Brasil.

IIIMáquinas Agrícolas, Faculdade de Engenharia Agrícola, UNICAMP, Campinas, SP, Brasil.. 


\section{INTRODUÇÃO}

A agricultura convencional, modelo predominante no Brasil e no mundo, tem sido apontada como responsável por danos ambientais e mau uso dos recursos naturais (IPCC, 2007), assim como pela intoxicação de trabalhadores rurais (CASTRO, 2006). A agricultura orgânica surgiu na década de 1920 como uma alternativa ao sistema convencional, preconizando uma produção sustentável nas perspectivas ecológica, econômica e social. A agricultura orgânica vem se desenvolvendo rapidamente e já é praticada em mais de 120 países do mundo. Atualmente cerca de 31 milhões de hectares são cultivados organicamente, por aproximadamente 634 mil agricultores. A Oceania detém 39\% da área agrícola orgânica, seguida pela Europa, com 23\%, e pela América Latina, com 19\%. O Brasil ocupa a 6 $6^{\mathrm{a}}$ posição mundial em termos de superfície ocupada com a agricultura orgânica, que já se estabeleceu em 842 mil hectares e absorve cerca de 15 mil produtores, a maior parte do tipo familiar, que representam 90\% do total(WILLER \& YUSSEFI, 2007).

O mercado de orgânicos tem sido apontado como o que mais cresce no Brasil ( $50 \%$ ao ano) e no mundo. Em 2003, a produção orgânica movimentou US $\$ 25$ bilhões no mundo e no Brasil US\$200 milhões em 2004 (BRASIL, 2005). Diversas pesquisas foram realizadas sobre a agricultura orgânica, tanto do ponto de vista técnico (manejo, produtividade, dentre outros) e econômico (retorno econômico da atividade e tendências), quanto dos aspectos ecológicos (preservação da água, solo, fauna e flora). No entanto, não se encontram pesquisas que tenham por objetivo discutir o trabalho na agricultura orgânica. Assim, não há um corpo de conhecimentos consolidado sobre o trabalho nesse sistema, bem como não existem indicadores que nos permitam avaliar os impactos que esse trabalho pode ter sobre a saúde e o bem-estar das pessoas, embora a exclusão da manipulação de biocidas tóxicos já constitua um grande avanço.

Percebe-se a necessidade e a importância do desenvolvimento de pesquisas que contemplem o ponto de vista do trabalho humano, não somente evidenciando o que o sistema orgânico tem de positivo para os agricultores, mas também identificando os aspectos que careçam de melhorias. Analisar o trabalho dos gestores na agricultura orgânica é o tema central deste estudo ergonômico, que teve como foco a organização do trabalho e a tecnologia utilizada nesse segmento, buscando ampliar a compreensão das atividades desenvolvidas, a complexidade que estas apresentam, as dificuldades encontradas e as estratégias de superação. Para a análise, foram selecionados os seguintes referenciais teóricos: a ergonomia franco-belga e a Teoria da Complexidade (TC) baseada nas ideias de Edgar Morin. A primeira justifica-se por permitir compreender o trabalho de uma forma mais ampla, ao se deter no trabalho real dos operadores, e a segunda, por buscar uma explicação mais rica dos fenômenos, que vá além do princípio da simplificação (separação/redução), e por se “constituir num esforço para conceber o incontornável desafio que o real lança na nossa mente” (MORIN, 2003).

AAnálise Ergonômica do Trabalho (AET) é oriunda da escola franco-belga de ergonomia e se fundamenta na análise das situações reais de trabalho, o que possibilita sua compreensão e transformação (GUÉRIN et al., 2001). Esse método é composto de três fases principais: a análise da demanda, a análise da tarefa e a análise da atividade. A análise da demanda consiste em analisar o problema inicialmente proposto pelos demandantes, delimitar o objeto de estudo e esclarecer suas finalidades. A análise da tarefa corresponde ao levantamento dos dados referentes aos objetivos e resultados esperados do trabalho e os meios disponíveis para realizá-lo. A análise da atividade consiste em compreender o trabalho que é efetivamente realizado, as dificuldades encontradas e as estratégias utilizadas para superá-las. No final, os dados levantados permitem formular hipóteses de trabalho que delineiam os rumos a serem seguidos, para que, ao final da análise, seja possível elaborar um diagnóstico e fornecer recomendações ergonômicas.

Embora haja complexidade sempre que há um sistema - inter-relações de elementos para formar uma unidade - e que, portanto, todo trabalho possa ser considerado complexo, elegeu-se o trabalho dos gestores na agricultura orgânica justamente por atuarem em sistemas de produção bastante diversificados. Para ampliar a compreensão dos resultados obtidos, adotou-se o paradigma da complexidade, que transcende o reducionismo científico clássico.

A TC é composta por 13 princípios de inteligibilidade, que ligados uns aos outros, auxiliam a compreensão dos fenômenos da realidade, procurando desenvolver um diálogo entre ordem, desordem e organização, mostrando além da multidimensionalidade a inseparabilidade dessas noções no mundo dos fenômenos. Não há privilégio nem da ordem (previsão) nem da desordem (incerteza), mas a relação que se estabelece entre ambas, de forma antagonista e paradoxalmente complementar, para formar a organização - aquilo que dá coerência constitutiva, regra, regulação e estrutura às interações. Essa visão complexa na concepção da organização integra o pensamento hologramático - no qual não só a parte está no todo, mas também o todo está na parte - 
facilitando a percepção da organização como recursiva, na medida em que os efeitos e produtos dela são necessários a sua própria causação e a sua produção (MORIN, 2003). Dito de outra forma, a organização, que é entendida aqui como a organização do trabalho na agricultura orgânica, não se resume em apenas alguns princípios de ordem ou algumas leis, mas também incorpora uma relação íntima com o meio ambiente, o que inclui os princípios de diversidade, aleatoriedade e incertezas, além da recursividade de seus fenômenos.

\section{MATERIAL E MÉTODOS}

Esta pesquisa, realizada em duas etapas, permitiu investigar o trabalho dos gestores em Unidades de Produção Agrícola Orgânica (UPAO), por meio da adaptação do método da Análise Ergonômica do Trabalho (AET) e da realização de entrevista estruturada em um questionário. Os dados de campo foram posteriormente interpretados à luz da Teoria da Complexidade (TC).

Na primeira etapa da pesquisa, realizada de abril de 2006 a fevereiro de 2007, foram empregadas 72 horas de observação de campo por meio da adaptação do método da Análise Ergonômica do Trabalho. Das três fases principais deste método (análise da demanda, da tarefa e da atividade), apenas a análise da demanda não foi realizada, já que não havia uma demanda socialmente formulada pelos trabalhadores. Ao contrário, a demanda foi de natureza acadêmica, orientada pelos objetivos desta pesquisa. Portanto, foi possível conhecer o trabalho dos gestores em duas unidades certificadas de produção orgânica de frutas e hortaliças do interior de São Paulo, localizadas em Jarinu e Itu. Estudaram-se detalhadamente as atividades desenvolvidas pelos gestores nessas UPAO, por meio de observações gerais e entrevistas abertas, que permitiram acompanhar e compreender seu trabalho durante o planejamento, a organização, a direção e o controle das áreas de produção, finanças, recursos humanos e comercialização. Essa etapa de observações concentrou-se em saber o que os gestores faziam, como faziam, as razões pelas quais faziam e, principalmente, quais as dificuldades encontravam e quais estratégias de superação utilizavam.

Posteriormente, em uma segunda etapa, com base nos conhecimentos já adquiridos sobre o trabalho dos gestores, elaborou-se um questionário que foi aplicado também a outros gestores de produção orgânica durante as entrevistas realizadas de maio a julho de 2007. Procurou-se verificar se as dificuldades e estratégias inicialmente observadas nas duas UPAO também se faziam presentes no trabalho dos outros gestores, bem como caracterizar e, em alguns casos, quantificar os principais elementos de complexidade.
Cada entrevista durou em média duas horas e meia. Foram entrevistados pessoalmente pela primeira autora 10 gestores de UPAO que se localizam próximas da cidade de Campinas e com produção certificada como orgânica. Cabe enfatizar que o número de entrevistados representa a maioria absoluta dos produtores orgânicos certificados de hortícolas e frutas num raio de $90 \mathrm{~km}$ de Campinas, o que confere um peso importante para esta pesquisa.

O instrumento elaborado permitiu indagar os gestores sobre a organização do trabalho e a caracterização da UPAO em termos de produção, procurando levantar elementos de diversidade e variabilidade, bem como a comercialização dos produtos, os tipos de clientes, a produtividade e o lucro, o autoconsumo e as fontes de conhecimentos e tecnologia. Outras questões abordaram as condições de trabalho, as características do trabalho do gestor em termos de planejamento, a organização, a direção e o controle da produção, bem como a natureza e frequência dos imprevistos, dos incidentes e das dificuldades. Os gestores foram questionados também sobre as vantagens e desvantagens de se trabalhar na agricultura orgânica e sobre as perspectivas de futuro, assim como sobre as possíveis demandas por pesquisa na área.

\section{RESULTADOS E DISCUSSÃO}

Na primeira etapa da pesquisa, verificou-se que grande parte das pessoas que trabalham na agricultura orgânica executa múltiplas tarefas relacionadas aos diversos sistemas de trabalho, existindo pouca especialização. Porém, os gestores são os responsáveis pela maioria das tarefas, atuando como administradores e executores do trabalho de produção. Suas atividades determinam posturas físicas desconfortáveis e incômodas e significativos esforços para realizar o trabalho na horticultura, especialmente durante o plantio, os tratos culturais e a colheita, pois as tarefas são predominantemente manuais e em apenas algumas delas é possível contar com o auxílio de mecanização.

Foi possível também evidenciar que os gestores realizam muitas atividades ligadas aos diversos sistemas de trabalho: produção (vegetal, animal e processamento), financeiro (contabilidade, impostos), recursos humanos (recrutamento, contratação, treinamento, pagamento) e comercialização (vendas, diferentes tipos de clientes), e que ainda se ocupam daquelas tarefas específicas ligadas à certificação orgânica. Cada um desses sistemas demanda, por parte dos gestores, o desenvolvimento de competências de natureza bastante diversa, incluindo muito conhecimento e precisão. 
Cabe destacar que o sistema de produção vegetal comporta várias fases ou subsistemas, tais como: preparo do solo, plantio, tratos culturais, colheita e beneficiamento/pós-colheita. Por sua vez, cada um desses subsistemas é constituído de constelações de tarefas e subtarefas que precisam ser organizadas ao longo do tempo. O sistema de produção animal comporta tarefas relacionadas com a alimentação, a reprodução, a biosseguridade (vacinas, limpeza, medicamentos) e outros manejos (como, por exemplo, tosquia, mochação, descorna). A grande variedade de atividades que foi observada está relacionada de forma direta à diversidade da produção, principalmente da produção vegetal. O número de cultivos, nas duas UPAO inicialmente pesquisadas, cuja área cultivada era de 4 e 12 ha respectivamente, era de 52 hortaliças e morangos na UPAO Jarinu e de 67 hortaliças e 16 frutas na UPAO Itu.

Percebeu-se que, para conseguir produzir tantos itens, o número de informações e conhecimentos que o gestor deve possuir é bastante significativo, pois cada cultivo tem exigências diferentes. É preciso ainda integrar esses cultivos com a produção animal e ainda planejá-los e distribuí-los ao longo do tempo, de acordo com as condições climáticas e o espaço disponível, bem como as demandas e exigências dos clientes. O gestor se constitui no protagonista na busca de soluções aos inúmeros problemas que se apresentam no cotidiano do trabalho da agricultura orgânica e, por meio das entrevistas realizadas na segunda etapa da pesquisa, cuja síntese é apresentada logo a seguir, foi possível generalizar essa afirmação.
Todos os gestores entrevistados trabalham em UPAO certificadas como orgânica (Tabela 1), que iniciaram a produção, em média, há mais de 11 anos. Nessas UPAO o gerenciamento é feito pelo produtor que é membro da família e que detém a propriedade da terra (total ou parcial), com exceção da UPAO 1, onde um profissional técnico foi contratado para esse fim.

Cabe destacar que $60 \%$ dos entrevistados trabalham diretamente na produção e na administração (administradores e executores concomitantemente), ou seja, são polivalentes, assumindo também as atividades ligadas à certificação, à comercialização e aos recursos financeiros e humanos. Os gestores abarcam ainda tarefas relacionadas ao turismo rural e à promoção de eventos em $40 \%$ das UPAO, assim como em $70 \%$ delas onde se faz reflorestamento, com uma grande variedade de espécies, o que demanda mais investimento financeiro, trabalho e conhecimento por parte desses gestores.

Existe uma variação considerável entre as UPAO em termos de área total (de 5 a 160ha) e cultivada (de 4 a 33ha), assim como na composição da força de trabalho (familiar e contratado), conforme pode ser visto na tabela 1. Porém, todas elas podem ser consideradas pequenas quando comparadas com os padrões convencionais da estrutura fundiária brasileira.

Na maioria das UPAO, além da produção vegetal, encontrou-se também a produção animal e o processamento de vários itens, e $40 \%$ delas se voltam ainda ao setor de serviços (turismo rural e eventos ligados à agroecologia). Desse modo, somente $30 \%$ das UPAO se dedicam exclusivamente à produção vegetal. As demais, além de trabalharem com uma grande variedade de cultivos (média aproximada de 34

Tabela 1 - Dados gerais das UPAO. Campinas, SP. Maio a Julho de 2007.

\begin{tabular}{|c|c|c|c|c|c|c|c|c|c|c|c|c|c|c|}
\hline \multicolumn{4}{|c|}{ 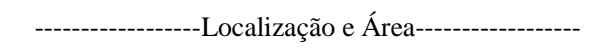 } & \multicolumn{8}{|c|}{ 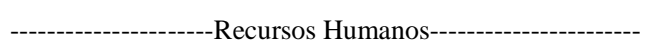 } & \multicolumn{3}{|c|}{---Itens de Produção--- } \\
\hline & & \multicolumn{2}{|c|}{----Área (ha)---- } & \multicolumn{3}{|c|}{--------Família------- } & \multicolumn{4}{|c|}{------Contratados------ } & \multirow{2}{*}{$\frac{\text { T. }}{\text { T.G. }}$} & & & \\
\hline UP & Local-SP & Cult. & $\mathrm{T}$. & TI & $\mathrm{TP}$ & $\mathrm{T}$. & $\mathrm{F}$ & M & $\mathrm{D}$ & $\mathrm{T}$. & & V. & A. & P. \\
\hline 1 & Itu & 12 & 30 & 2 & 0 & 2 & 12 & 0 & 2 & 14 & 16 & 81 & 2 & 12 \\
\hline 2 & Jarinu & 4 & 5 & 3 & 3 & 4,5 & 0 & 0 & 0 & 0 & 4,5 & 54 & 0 & 2 \\
\hline 3 & Jaguariúna & 33 & 60 & 18 & 1 & 18,5 & 14 & 0 & 0 & 14 & 32,5 & 60 & 1 & 4 \\
\hline 4 & Jarinu & 4 & 8,5 & 1 & & 1 & 2 & 0 & 0 & 2 & 3 & 4 & 0 & 0 \\
\hline 5 & Valinhos & 4 & 7 & 2 & 2 & 3 & 4 & 0 & 0 & 4 & 7 & 45 & 0 & 0 \\
\hline 6 & Jaguariúna & 9 & 14 & 4 & 1 & 4,5 & 0 & 0 & 1 & 1 & 5,5 & 25 & 0 & 7 \\
\hline 7 & Santo Antônio Posse & 30 & 160 & 2 & 2 & 3 & 15 & 0 & 0 & 15 & 18 & 28 & 1 & 2 \\
\hline 8 & Indaiatuba & 18 & 36 & 1 & 1 & 1,5 & 3 & 11 & 0 & 14 & 15,5 & 26 & 4 & 3 \\
\hline 9 & Paulínia & 9,7 & 17 & 2 & 0 & 2 & 5 & 0 & 0 & 5 & 7 & 9 & 0 & 0 \\
\hline \multirow[t]{2}{*}{10} & Serra Negra & 19 & 100 & 1 & 1 & 1,5 & 6 & 7 & 2 & 15 & 16,5 & 6 & 6 & 10 \\
\hline & Média & 14,3 & 43,7 & & & & & & & & 13 & 34 & 1 & 4 \\
\hline
\end{tabular}

Legenda - UP=Unidade de Produção; Cult.=Cultivada; T=Total; TI=Tempo Integral; TP=Tempo Parcial (0,5 Pessoa); F=Funcionário Registrado; M=Meeiro; D=Diarista; T.G=Total Geral; V=Vegetal; A=Animal; P=Processamento.

Ciência Rural, v.40, n.2, fev, 2010. 
itens e máximo de 81), dedicam-se ainda à produção animal (50\% das UPAO) e em 70\% das UPAO se faz algum tipo de processamento (mínimo de dois e máximo de 12 itens). A produção vegetal predominante é de hortaliças, seguida da de frutas e em três UPAO ainda se cultivam cereais. A produção animal, apesar de ocorrer em apenas metade das UPAO, é bem variada, e ovos, leite e mel são os produtos que mais prevaleceram.

Os gestores da produção orgânica precisam fazer também a gestão financeira, do patrimônio e do entorno da UPAO, administrando assim suas relações com o meio exterior: clientes/mercado; fornecedores; parceiros (outros produtores com quem ocorre a maior fonte de troca de informações/tecnologias: 100\%); inspetores da certificadora; técnicos e vizinhos. Eles necessitam ainda realizar a gestão do próprio tempo de trabalho, já que são administradores e executores da produção.

Das dificuldades apontadas nas entrevistas, ganham destaque: os esforços físicos (80\%); as posturas desconfortáveis e incômodas (90\%); o esforço mental (90\%); a falta de recursos tecnológicos para controlar pragas e doenças (80\%) e para atingir a qualidade desejada (80\%); a falta de assistência técnica (70\%); as relacionadas com a falta de recursos financeiros associadas à falta de acesso a crédito (80\%) e ao alto custo da produção (80\%); relacionadas aos recursos humanos, principalmente para encontrar pessoas qualificadas (80\%) e que permaneçam no campo. Outras dificuldades relatadas foram: tomar decisões (70\%); obter lucro (70\%); lidar com a comercialização (60\%); responder às normas da certificação, pois envolvem tarefas burocráticas (80\%) e determinam regras não muito claras ou difíceis de serem cumpridas (40\%), além de seu alto custo (60\%). AHRENS (2006), DAROLT(2002) e GEMMA(2004) já relataram algumas dessas mesmas dificuldades em seus respectivos estudos.

Uma característica importante e singular do trabalho dos gestores da produção orgânica é que lhes cabe fazer a gestão “ecológica” da UPAO, ou seja: se encarregarem da certificação orgânica e do cumprimento da legislação ambiental, além de conhecerem e administrarem as questões relacionadas ao clima (calendário, astronomia), arranjo espacial, consorciação, rotação de cultivos e pousio. Esses gestores também fazem a preservação dos recursos naturais (solo, água), a recuperação de áreas degradadas, a recuperação de nascentes e o reflorestamento (70\%). Destaca-se que, em uma UPAO, já foram plantadas 125 espécies nativas. Eles ainda realizam também a gestão dos recursos humanos, seja do trabalho familiar ou do contratado, o que $50 \%$ deles acha difícil e complexo, além da gestão da vida familiar e social, pois a vida familiar está integrada à produção, devido ao fato de a maioria residir na própria UPAO.

Em resumo, verificou-se que esses trabalhadores gerem o que se pode denominar de um macrossistema (Figura 1) composto de diversos sistemas e subsistemas que precisam ser por eles integrados. Fazem parte desse macrossistema os sistemas de produção - vegetal, animal, processamento e serviços - cada um deles com sua diversidade, e as outras áreas que se relacionam com os sistemas de produção - administração, finanças, comercialização, manutenção, compras, recursos humanos, recursos técnico-agronômicos, bem como a gestão ecológica, do patrimônio e da vida social e familiar. Por fim, ainda é preciso realizar a integração desse macrossistema com seu entorno, por meio do relacionamento que o gestor estabelece com fornecedores, vizinhos, parceiros, clientes, técnicos e inspetores da certificadora.

A diversidade se faz muito presente no trabalho dos gestores, não somente pelas características do macrossistema, mas também pela natureza de seu trabalho polivalente e dos conhecimentos e relacionamentos que ele necessita desenvolver para atingir os objetivos da produção orgânica. A figura 1 foi criada na tentativa de mostrar não somente as áreas que o gestor precisa administrar, mas também a integração e o equilíbrio que ele deve manter entre elas, lembrando que esse equilíbrio é sempre dinâmico e instável. A cada desequilíbrio novas estratégias são desenvolvidas pelo gestor a fim de garantir a sustentabilidade da UPAO, que, por sua vez, comporta muitas incertezas e contradições.

A complexidade do trabalho do gestor na agricultura orgânica se relaciona com toda essa diversidade inerente ao próprio manejo e a necessidade de integrar múltiplas dimensões, demandando o desenvolvimento e a integração de variados saberes e competências a fim de criar uma organização do trabalho dinâmica, como aquela descrita na TC de Edgar Morin, que precisa ser frequentemente reconstituída devido ao grande número de interações e de relações complementares e antagonistas entre ordem e desordem, equilíbrio e desequilíbrio (Figura 2).

$\mathrm{Na}$ figura 2, observa-se o ciclo da organização na perspectiva da complexidade. Essa organização precisa ser reconstituída pelo gestor da produção orgânica porque toda solução produz nova questão - que comporta em si a ordem e a desordem. Quando o equilíbrio entre as dimensões ecológicas, econômicas e sociais é alcançado, o macrossistema 


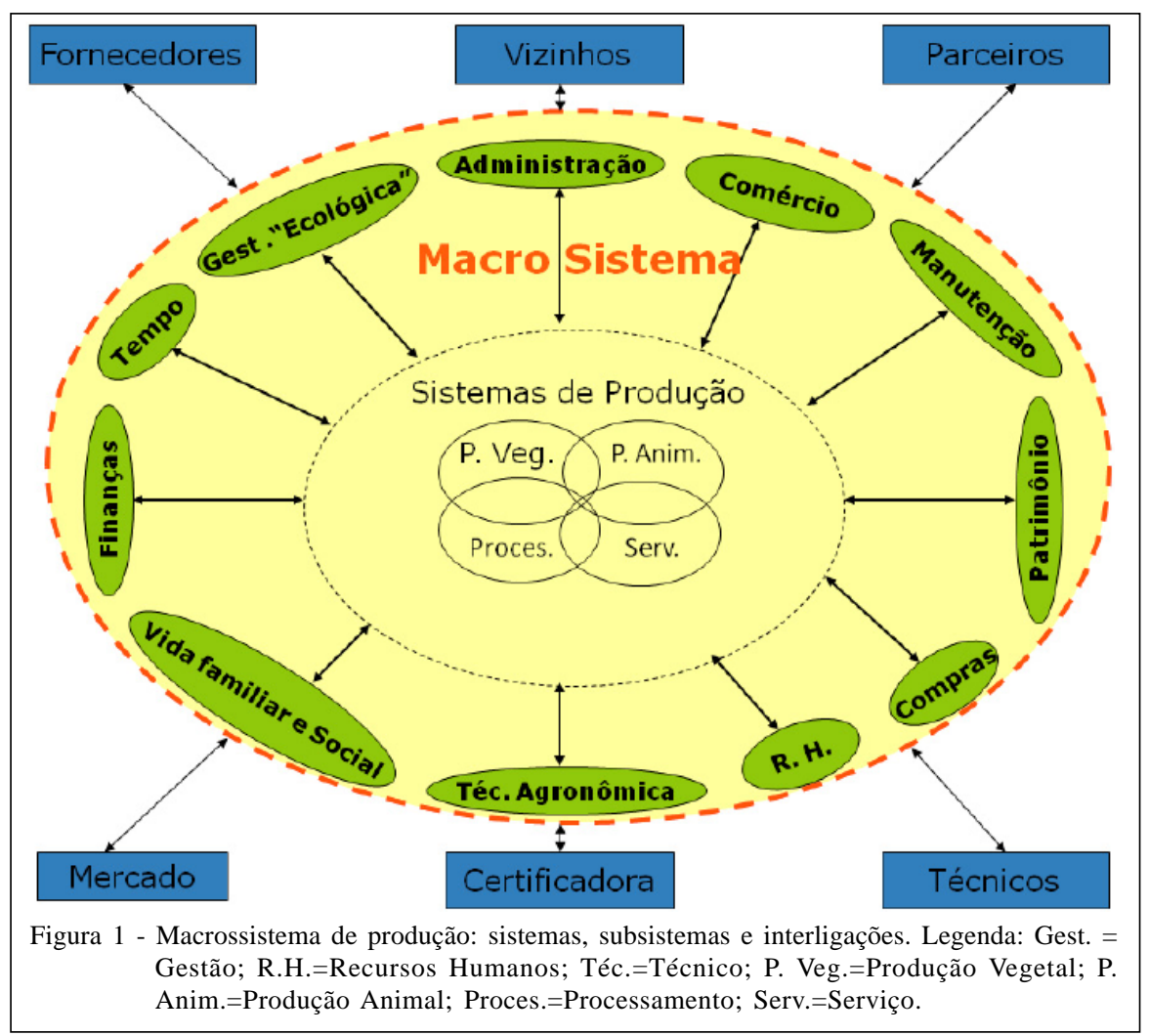

está mais próximo da sustentabilidade. Porém, como esse equilíbrio é dinâmico e instável, surgem outras questões dentro da própria organização, causando desequilíbrio, que demanda então novas estratégias do gestor. Essas interações promovidas pelo gestor no macrossistema objetivam o seu reequilíbrio. Constata-se assim que a organização precisa então ser concebida como "reorganização", pois o macrossistema tende invariavelmente a desorganizarse, determinando uma reorganização permanente de si num ciclo contínuo.

Muitas pesquisas ainda precisam ser realizadas para eliminar os entraves e as dificuldades que se impõem aos agricultores orgânicos, especialmente sobre as questões técnicas e de saúde e conforto, além daquelas relacionadas com a comercialização, a certificação e o acesso a crédito. Será necessário ainda desenvolver políticas públicas que favoreçam a assistência e o suporte técnico adequados. Somente a integração de vários esforços contribuirá para o desenvolvimento desse setor, não somente em termos de produtividade e qualidade, mas também de melhorias para o trabalho e a qualidade de vida dos agricultores. A visão do trabalho que a ergonomia proporciona pode contribuir para a ampliação do corpo de conhecimentos da produção orgânica, na tentativa de que carregue em si as bases para um "trabalho humano mais sustentável" na agricultura.

\section{CONCLUSÃO}

A sustentabilidade ecológica que o manejo orgânico pressupõe traz uma diversidade muito grande para o trabalho dos agricultores, em especial para o trabalho dos gestores, que precisam desenvolver estratégias originais para enfrentar as dificuldades de natureza bastante variada, incertezas e contradições nos moldes descritos na Teoria da Complexidade.

Além da sustentabilidade ecológica, é necessário que os gestores garantam a viabilidade econômica e mantenham relações sociais e de trabalho justas, para atender aos outros preceitos de sustentabilidade. Para tanto, além de manejar adequadamente os diversos tipos de produção e proteger os recursos naturais, esses agricultores incorporam, integram e mais especificamente “traduzem” esses princípios em práticas agrícolas, equilibrando dimensões por vezes tão contraditórias como as ecológicas e econômicas.

O gestor da produção orgânica é geralmente administrador e executor do trabalho e sua contribuição é bastante significativa para o desenvolvimento da produção, visto que assume também todas as funções administrativas de planejamento, organização, direção e controle em todas as áreas: produção, manutenção, finanças, recursos humanos e comércio. O gestor se responsabiliza ainda por uma verdadeira gestão ecológica, ou seja, pelas questões ligadas à certificação 


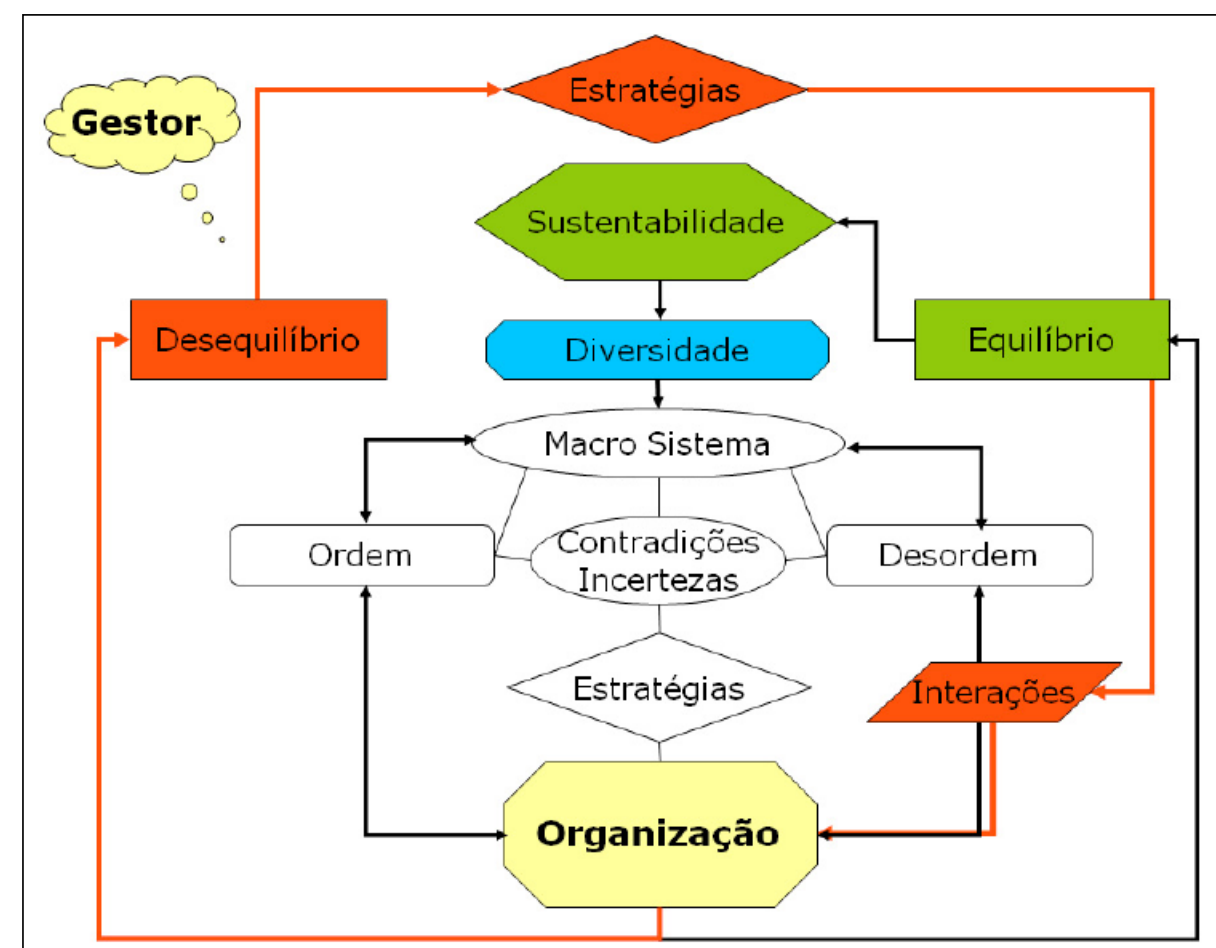

Figura 2 - O ciclo da organização da UPAO na perspectiva da complexidade.

e à legislação ambiental, ao reflorestamento e à conservação dos recursos naturais.

Dessa forma, o gestor pensa a UPAO de forma integrada e sistêmica, constrói saberes por meio de uma abordagem complexa, entendendo-a e tratandoa como um ser vivo, observando e identificando os elementos que possam auxiliá-lo na tomada de decisões num ambiente onde não se dispõe de tecnologia adequada, com poucos recursos financeiros e sem assessoria técnica.

\section{AGRADECIMENTOS}

À Coordenação de aperfeiçoamento de Pessoal de Nível Superior (CAPES) e à Fundação de Apoio à Pesquisa do Estado de São Paulo (FAPESP), respectivamente, pela bolsa de doutorado e pelo financiamento desta pesquisa, por meio de um projeto do GETA (Grupo Ergonomia, Trabalho e Agricultura) da FEAGRI/UNICAMP.

\section{REFERÊNCIAS}

AHRENS, D.C. (Coord.). Rede de propriedades familiares agroecológicas: uma abordagem sistêmica no CentroSul do Paraná. Londrina: Instituto Agronômico do Paraná, 2006. 79p.

BRASIL. Portaria n. 86, de 03 de Março de 2005. Norma Regulamentadora de Segurança e Saúde no Trabalho na Agricultura, Pecuária, Silvicultura, Exploração Florestal e Aqüicultura - NR 31. Diário Oficial da União, 4 mar. 2005. Ministério do Trabalho e Emprego. Disponível em: <http:// www.mte.gov.br/legislacao/normas_regulamentadoras/ nr_31.pdf $>$. On line. Acesso em: 30 de nov. 2005.

CASTRO, F. Perigo crescente. Boletim da Agência de Notícias da Fundação de Amparo à Pesquisa do Estado de São Paulo - FAPESP. 08/11/2006. Disponível em: <http://www.agencia.fapesp.br/ boletim_print.php?data[id_materia_boletim]=6313>. Acesso em 14 nov. 2006

DAROLT, M.R. Agricultura orgânica: inventando o futuro. Londrina: IAPAR, 2002. 250p.

GEMMA, S.F.B. Aspectos do trabalho agrícola no cultivo orgânico de frutas: uma abordagem ergonômica. 2004. $176 \mathrm{f}$. Dissertação (Mestrado em Engenharia Agrícola, Área de Concentração Máquinas Agrícolas) - Faculdade de Engenharia Agrícola, UNICAMP, Campinas, SP.

GUÉRIN, $F$ et al. Compreender o trabalho para transformá-lo: a prática da ergonomia. São Paulo: Edgard Blucher, 2001. 201p.

IPCC. Climate change 2007: the physical science basis: summary for policymakers. In: ALLEY, R. et al. (Eds). Contribution of Working Group I to the Fourth Assessment Report of the Intergovernmental Panel on Climate Change. 2007. 18p. Disponível em: <http://www.ipcc.ch/pdf/assessment-report/ar4/ wg1/ar4-wg1-spm.pdf>. Acesso em: 19 dez. 2007.

MORIN, E. Ciência com consciência. 7.ed. Rio de Janeiro: Bertrand Brasil, 2003. 350p.

WILLER, H.; YUSSEFI, M. Organic farming worldwide 2007: Overview \& Main Statistics. In: The world of organic agriculture - Statistics and emerging trends 2007. Disponível em: <http://orgprints.org/10506/01/willer-yussefi2007-p1-44.pdf>. On line. Acesso em: 04 jul. 2007. 